\title{
Frontal lobe dementia and motor neuron disease
}

\author{
D Neary, J S Snowden, D M A Mann, B Northen, P J Goulding, N Macdermott
}

\begin{abstract}
Four patients are described, in whom a profound and rapidly progressive dementia occurred in association with clinical features of motor neuron disease. The pattern of dementia indicated impaired frontal lobe function, confirmed by reduced tracer uptake in the frontal lobes on single photon emission computed tomography (SPECT). Pathological examination of the brains of two patients revealed frontal-lobe atrophy, with mild gliosis and spongiform change. The spinal cord changes were consistent with motor neuron disease. The clinical picture and pathological findings resembled those of dementia of frontal-lobe type and were distinct from those of Alzheimer's disease. The findings have implications for the understanding of the spectrum of non-Alzheimer forms of primary degenerative dementia.
\end{abstract}

The association between dementia and motor neuron disease has become increasingly recognised over recent years. ${ }^{1}$ Formerly identified as part of the Dementia-Parkinsonism complex occurring commonly on the Pacific island of Guam, ${ }^{23}$ there have since been several reports of the association from $\mathrm{Japan}^{4-6}$ and from Western countries. ${ }^{7-11}$ However, the pattern of mental change and its relationship to other forms of dementia remains unclear. Four patients, in whom the diagnosis of presenile dementia with motor neuron disease was made during life, have been studied longitudinally. Comprehensive clinical analysis, including both qualitative and quantitative assessment of mental function, has permitted the identification of characteristic features of the dementia accompanying motor neuron disease, which could be compared with characteristics of other forms of primary degenerative dementia. The brains of two patients have been studied at necropsy, permitting an examination of clinico-pathological relationships.

\section{Case histories}

In none of the four patients was there any previous medical or psychiatric history. There had been no occupational exposure to chemicals or heavy metals. They had never suffered a major head injury and there was no evidence of alcohol abuse. There was a family history of dementia in patient 2 only.

\section{Patient 1}

A 52 year old male security officer presented with a 12 month history of personality change. Formerly equable and conscientious, he became rude and verbally aggressive, and progressively more withdrawn and unmotivated, his sole remaining interest being in food. He continued to carry out activities of daily living independently.

Physical examination General examination was normal. Neurological examination revealed slight weakness of the right side of the face, dysarthria, weak cough and gag reflex, wasting and fasciculation of the tongue. The jaw jerk was exaggerated. Muscular power was normal but there was a mild spastic increase in tone in the lower limbs. There were fasciculations of the muscles of the shoulder girdle and the biceps. Tendon jerks were brisk, the plantar responses flexor and abdominal reflexes present. Sensation, coordination and gait were normal.

Mental examination He had a bland, unconcerned affect and he lacked insight. His behaviour was mildly disinhibited. Examination of his conversational speech, comprehension, repetition, word finding, reading and writing revealed no linguistic impairment. $\mathrm{He}$ performed normally on the abbreviated Token test ${ }^{12}$ and Boston naming test. ${ }^{13}$ However, he exhibited concreteness of thinking, with literal interpretations of metaphors and proverbs. There was no evidence of perceptual, spatial or praxic disorder. He identified objects, line drawings of objects and faces of celebrities. $\mathrm{He}$ could locate objects in the room, track the Money road $\mathrm{map}^{14}$ and reproduce nonrepresentational hand postures. His spontaneous drawing of a house and copies of a cube and abstract figures were normal, with preserved spatial configuration. $\mathrm{He}$ could reproduce Koh's block figures. He had no dressing difficulty. He could demonstrate actions by gesture and pantomime.

$\mathrm{He}$ was fully orientated for time and place and gave a good account of day to day events. $\mathrm{He}$ could summarise fable-like short stories immediately after reading them aloud and recalled them to a comparable level of proficiency after a one hour delay. On the Warrington word and face recognition tests ${ }^{15}$ he scored respectively $40 / 50$ and 39/50, lying at the 10th percentile for his age group. On a paired-associate task he failed to learn six pairs of unrelated words over six learning trials. However, when provided with a visual image strategy he could learn a matched set of unrelated word pairs on the first trial. He recalled all word pairs after a one hour delay without additional training.

Assessment with the WAIS ${ }^{16}$ yielded a 
Table 1 WAIS age-scaled scores (patient 4 not testable)

\begin{tabular}{lrrr}
\hline & \multicolumn{3}{l}{ Patient } \\
\cline { 2 - 4 } & 1 & 2 & 3 \\
\hline Verbal & 7 & 4 & 1 \\
Information & 8 & 10 & 4 \\
Digit Span & 7 & 7 & 1 \\
Vocabulary & 8 & 4 & 2 \\
Arithmetic & 5 & 6 & 1 \\
Comprehension & 2 & 4 & 2 \\
Similarities & 10 & 7 & 2 \\
Performance & 6 & - & 2 \\
Picture completion & 10 & 6 & 5 \\
Picture arrangement & 12 & 7 & 4 \\
Block design & 6 & 7 & 2 \\
Object assembly & & & \\
Digit symbol & &
\end{tabular}

verbal IQ of 77, performance IQ of 91 and full scale IQ of 83. Disparities between subtest scores (table 1) are of relevance. The low "comprehension" score arose since his responses reflected personal anecdotes rather than generalisations. The poor scores on the "similarities" sub-test reflect a consistent tendency to identify differences rather than similarities between pairs of objects. In the picture arrangement task he left pictures essentially in their original order. He could itemise elements within individual pictures but did not attempt to integrate these into a coherent whole. On the National Adult Reading Test ${ }^{17}$ he achieved an error score of 30 , which yields a predicted verbal IQ of 101 and performance IQ of 104 . Using a $5 \%$ cut-off the discrepancy between predicted and obtained IQ is highly significant for the verbal scale but does not reach significance for the performance scale.

He performed poorly on tasks sensitive to frontal lobe dysfunction, that make demands on abstraction, planning and mental flexibility. On the modified version of the Wisconsin card sorting test ${ }^{18}$ he achieved two categories only. Despite reminders of the test instructions he persistently sorted cards with those previously placed, rather than according to the four stimulus cards. On the Weigl's block task ${ }^{19}$ he achieved one method of grouping only. When blocks were grouped by the examiner he could identify the underlying sorting criterion in one case only, on subsequent trials displaying perseveration of this original sorting rule. In a task based on the " 20 questions" principle, ${ }^{20}$ which requires the subject to identify a "target" picture presented amongst alternatives by asking questions yielding a yes/no response, performance was concrete and lacking in strategy. He pointed to individual pictures at random and made no attempt to generate questions that would eliminate the greatest number of alternatives.

Investigations Routine biochemical, haematological and serological investigations were normal. Electroencephalography was normal. Computed tomography (CT) did not show evidence of cerebral atrophy. Single photon emission computed tomography (SPECT) using ${ }^{99 \mathrm{~m}}$ Tc-HMPAO revealed reduced uptake of tracer in the left frontal region of the brain with preservation of uptake in the posterior cerebral hemispheres. Neurophysiological studies demonstrated normal motor nerve conduction velocities and sensory action poten- tials. Concentric needle electromyography of muscles of the upper and lower limbs revealed abundant multifocal fasciculation, motor unit potentials as great as $10 \mathrm{mV}$, and reduced interference pattern, compatible with motor neuron disease.

Progression His condition deteriorated dramatically over the ensuing six months. However, for geographical reasons re-examination was not possible.

\section{Patient 2}

A 58 year old labourer presented with an 18 month history of personality change and disordered conduct. Formerly sociable and considerate he became thoughtless and callous. He was restless and impatient and could no longer apply himself constructively to tasks. Previously an occasional Bingo player he became obsessed with the game. Yet, he would miss the numbers called because of poor concentration. He lost his former meticulous table manners and would cram food into his mouth and eat noisily. He had developed an abnormal fondness for chocolates. He was noted to feel the cold more than before. One year after the onset of his symptoms his behaviour was more overtly disinhibited: he would shout and swear in public and appeared oblivious to social mores. Although previously little interested in sexual relations he became obsessed with sex and would proposition females indiscriminately, including an aunt of 80 years. Approximately nine months after the onset of his mental symptoms he developed weakness of the arms and six months later of the legs. In the two months before investigation he had developed slurring of speech and difficulty in swallowing. The patient denied mental or physical difficulties and despite his weakness persisted in driving his car, professing himself competent to do so.

The patient's mother had had a similar change in personality and conduct when aged 60 years. She had neglected personal hygiene and self-care and refused to eat. When her family stocked her larder for her she had posted the food through neighbours' letter boxes. She too had become obsessed with the game of Bingo. She had begun to drink heavily, resulting in falls. She had been admitted to an elderly persons home where she had been aggressive and disinhibited. She had wandered incessantly. In contrast to her mental difficulties she had remained physically well, and there was no report of weakness, difficulties in swallowing or slurring of speech, even in advanced disease. She had died aged 74 years. No necropsy was undertaken.

Physical examination General examination on patient 2 was normal. Neurological examination revealed dysarthric and dysprosodic speech, tongue wasting and fasciculation. Profuse fasciculation was noted in the trunk and all four limbs, with marked wasting and weakness particularly in the upper limbs. Tone was normal. Reflexes were all brisk and the plantar responses extensor. Pout and grasp reflexes were elicited, the latter more marked 
on the right. Sensation and coordination were normal.

Mental examination $\mathrm{He}$ had an unconcerned demeanour, was inattentive and restless and performance was perfunctory. Speech output was reduced. He rarely initiated conversation and often gave monosyllabic replies to questions. He could follow simple verbal instructions and understand syntactically complex sentences. However, he demonstrated concreteness of thought in the interpretation of metaphor and proverb. Repetition of digits and polysyllabic words was unimpaired. Naming to confrontation and from description revealed a mild anomia. On the Boston naming test ${ }^{13}$ he named only 32 of 60 items, the predominant error type being the substitution of a description of the object's function for its name. Perseveration of previous responses occurred. He could read aloud, write his name and address without spelling error and carry out three digit mental and written calculations accurately.

There was no evidence of perceptual or spatial disorder. He could identify objects, line drawings of objects and faces of celebrities. He could locate objects in the environment and when dressing could orient clothing. He could trace the dotted line through the Money road map. ${ }^{14}$ Errors in the interpretation of pictorial scenes appeared secondary to impulsivity, inattention and failure to check his responses: performance could be improved by coaxing and encouragement. Performance on visuoconstructional tasks was compromised by his physical disorder. Nevertheless he succeeded in completing simple Koh's block designs. In reproducing rhythms tapped on the table, he displayed motor perseveration. He was fully orientated and could give an accurate autobiographical account of day to day events. However, he failed to generate information about current news events. Moreover, performance on formal memory tests was poor: Warrington word recognition ${ }^{15} 27 / 50$, face recognition 30/50. Assessment with the WAIS $^{16}$ yielded a verbal IQ score of 78 , performance score of 81 and full scale IQ of 79 (table 1). On the National Adult Reading Test ${ }^{17}$ he achieved an error score of 28 , corresponding to a predicted premorbid IQ of 105 . The discrepancy between predicted and obtained results is significant.

Performance on tests sensitive to frontal lobe dysfunction was impaired. On the card sorting test $^{18}$ he achieved one sorting category only. $\mathrm{He}$ persisted in sorting with respect to that same category throughout the test $(100 \%$ perseverative errors). On the Weigl block task ${ }^{19}$ he failed to achieve any correct groupings. $\mathrm{He}$ showed concreteness of thought, placing blocks together to form pleasing designs rather than according to a common dimension. He failed to identify the sorting criterion when blocks were grouped for him. In the " 20 questions" task ${ }^{20}$ he exhibited concreteness of thought and no concerted strategy for efficient identification of the target item. In a verbal fluency test he produced only nine animal names and six words beginning with the letter " $F$ " in one minute. In a design fluency test ${ }^{21}$ he failed to observe the frequently reiterated instruction that designs should be constructed from four lines only. There was perseveration of responses from a previous task.

Investigations Electroencephalography was normal. CT revealed cerebral atrophy with fronto-temporal predominance. SPECT demonstrated reduced uptake of tracer in both frontal lobes more marked in the left hemisphere. Neurophysiological examination revealed normal motor nerve conductions and sensory action potentials. Concentric needle electromyography revealed profuse, widespread fasciculation and fibrillation, compatible with motor neuron disease.

\section{Patient 3}

A 44 year old warehouse manager presented with an 18 month history of progressive deterioration in behaviour and intellect. Formerly conscientious, he neglected domestic and occupational responsibilities, and when sacked from work showed no concern. He had become self-centred, callous and lacking in emotional empathy. His thinking was rigid and inflexible and he became aggressive if his wishes were thwarted. He behaved impulsively and unpredictably, for example, attempting to remove the battery from his car while the engine was running. He was increasingly restless, and would wander the house and local streets, always keeping to the same route. Although superficially active he lacked persistence in tasks, so that his activities were essentially unconstructive. $\mathrm{He}$ became increasingly gluttonous, raiding the food cupboard surreptitiously, and invariably spending "pocket-money" on sweets voraciously eaten. He lost interest in sexual relations. He conversed less and had difficulty finding words and would substitute semantically related alternatives, for example "windows" for "curtains". His comprehension appeared impaired, although his contrary behaviour suggested wilfulness. He was "forgetful" and could not carry out simple shopping errands. He could wash, dress and shave himself and could negotiate his environment without becoming lost.

Physical examination General examination was normal. Neurological examination revealed fasciculation of the tongue and a positive jaw jerk. Speech was dysprosodic but not dysarthric. Power and tone were preserved but there was wasting of the small muscles of the hands and widespread fasciculations in the muscles of the upper limbs and shoulder girdle. Snout, suck and grasp reflexes were elicitable and the tendon jerks were very brisk. The plantar responses were flexor and abdominal reflexes were present. Sensation and coordination were normal.

Mental examination $\mathrm{His}$ affect was bland, and he had a fatuous grin. He denied mental and physical symptoms and showed no concern or curiosity regarding his predicament. While superficially cooperative he lacked persistence in tasks and was restless, frequently leaving the 
room. He responded rapidly and impulsively, without checking the accuracy or relevance of his responses. He demonstrated a marked economy of mental effort.

Speech output was reduced. He rarely initiated conversation. Answers to questions, when relevant, were economical and unelaborated. Stereotyped reiteration of words and phrases was common. No literal paraphasic errors were detected. He could understand simple nominal terms, but not complex syntax. On the Token test ${ }^{12}$ he scored 11/36. He repeated five digits correctly, but made sequencing errors in repeating word strings. He showed word finding difficulty to confrontation and from description and perseverations of previous responses occurred. Performance on the Boston naming test ${ }^{13}$ was impaired (30/ 60 correct), the predominant error type being semantic category substitutions, for example responding "zebra" for camel. His reading performance was variable: omissions or misreading of words occurred sporadically, unrelated to the linguistic difficulty of the material and suggested inattention to the task. In writing to dictation omissions and perseverations of words occurred. He failed to carry out the simplest mental and written calculations.

Perceptual and spatial abilities appeared largely intact. He had no difficulty locating objects and could find his way around the environment. He could identify line drawings of objects, traced the path through the Money road map ${ }^{14}$ with ease, and could localise towns on a map of Great Britain. He could copy nonrepresentational hand postures and his drawings and block constructions revealed preserved spatial configuration. Evaluation was, however, complicated by his perfunctory performance. He failed to name faces of contemporary celebrities, although comments suggested awareness of their identity. He could manipulate objects dextrously and could use gesture and pantomime accurately. However, he had sequencing difficulties in copying a series of hand postures and he could not copy simple motor rhythms. In an alternating hand movement task he perseverated an earlier set of responses. Performance on formal tests of memory was invariably impaired. Scores on the Warrington word and face recognition test ${ }^{15}$ were at chance level. Nevertheless he was orientated in time and place and could recall personal day-to-day events.

Standardised psychological assessment yielded a WAIS ${ }^{16}$ verbal IQ of 55 , performance IQ of 60 and full scale IQ of 53 (table 1). He failed to acquire the appropriate mental set for carrying out tasks, responded idiosyncratically or perseverated from one subtest to another. In the picture arrangement subtest he merely described individual pictures but made no attempt to order them logically. Similarly, in the picture completion test he identified the pictures but made no attempt to detect a missing part. His answers in the comprehension test were not pertinent. On the National Adult Reading Test ${ }^{17}$ he made 40 errors, yielding a predicted premorbid IQ of 95 . Given his impulsive mode of responding, yielding errors such as "apache" for ache, "asbestos" for abstemious, it is likely that his predicted IQ score represents an underestimate of his premorbid capabilities. The discrepancy between predicted and obtained IQ scores is highly significant.

$\mathrm{He}$ performed grossly abnormally on all tasks sensitive to frontal lobe dysfunction. In the modified card sorting test ${ }^{18}$ he achieved one sorting dimension only. Ninety eight per cent of errors were perseverative. In the Weigl's block task $^{19}$ he grouped blocks arbitrarily. When they were grouped for him he could not identify the underlying sorting rule. In a verbal fluency task he produced in one minute only seven animal names and one word beginning with " $F$ ". Design fluency ${ }^{21}$ performance was perseverative, concrete and not constrained by the four-line rule imposed by the task: he produced a succession of circles, triangles and squares. He scored 13 on the Shallice Evans Cognitive Estimation test. ${ }^{22}$

Investigations Electroencephalography was normal. CT revealed generalised cerebral atrophy with enlargement of the ventricles and cortical sulcal spaces. SPECT demonstrated marked decrease in uptake of tracer, most prominent in frontal regions. Neurophysiological investigations showed normal motor nerve conduction and sensory action potentials. Concentric needle electromyography of muscles of the upper and lower limbs revealed abundant multifocal fasciculation and some giant motor unit potentials. The results were compatible with anterior horn cell disease.

A needle biopsy, taken from the right frontal lobe, revealed no specific pathology in the cerebral cortex. In particular, there was no evidence of spongiform change, nor of glial reaction, and no senile plaques, neurofibrillary tangles or Pick bodies were present.

Progression His condition deteriorated rapidly over the ensuing six months, necessitating his institutional care. There was evident wasting of the muscles of the shoulder girdle in addition to the small muscles of the hand. Fasciculations were now evident in the lower limbs. Plantar responses were flexor and abdominal reflexes present. Sensation and coordination remained normal. He had a fatuous staring expression and grinned inanely. He rushed about purposelessly, retaining a surprising physical agility. He had acquired a stereotyped behaviour pattern of undressing and getting into bed at intervals throughout the day, getting up and dressing again only minutes later. He did not sleep during the day, but slept about 12 hours nightly. He was able to feed, dress and wash himself without difficulty.

Formal mental testing was no longer possible. He could not be persuaded to remain in one place for more than a few minutes. He volunteered no conversation, and responses to questions were monosyllabic or stereotyped phrases, often perseverative and inappropriate. Echolalia occurred, particularly of the final noun in a question. No literal paraphasias were evident. Speech was both dysprosodic and dysarthric. Assessment of comprehension was 
complicated by the paucity of his responses. He obeyed simple commands requiring whole body and limb movements and he could understand simple nominal terms and name some common objects on confrontation. It is likely, nevertheless, that his powers of comprehension were restricted. Repetition was limited to one word only, usually the last one given. When overlearnt series such as the days of the week were initiated for him he could produce the next item in the sequence but could not be induced to continue the series. His writing and drawing showed marked perseveration. His continuing ability to dress, locate objects and negotiate his environment indicated the absence of spatial disorder.

He died aged 45 years, approximately 28 months after disease onset and necropsy was carried out.

\section{Patient 4}

A previously conscientious 45 year old heavy goods vehicle driver lost his job through lack of punctuality. His wife noticed that he became increasingly apathetic and he abandoned his former interests in gardening, amateur dramatics and music. He stopped showing affection towards his family and became prone to aggressive outbursts, which were out of character. Without becoming lost, he would wander off on his own. His mental state deteriorated dramatically over the ensuing 18 months, culminating in his referral to a neurological centre. He would spend the day pacing the room and made no spontaneous attempt to dress or wash himself. His speech output had progressively diminished, and he had taken to laughing spontaneously and rubbing his hands together. He had lost $19 \mathrm{~kg}$ in weight during a period of two months. There was no history of physical symptoms including weakness.

Physical Examination The general examination was normal. Neurological examination revealed a brisk jaw jerk. Power and tone of muscles was preserved but there was evident wasting of the muscles of the shoulder girdle, upper arms and small muscles of the hands. Widespread fasciculations were present in the upper and lower limbs. Tendon reflexes were brisk, the plantar responses were flexor and the abdominal reflexes present. It was possible to elicit pouting, sucking and grasping reflexes. Sensation, coordination and gait were normal. Mental Examination $\mathrm{He}$ maintained a fatuous grin and on making eye contact with the interviewer he giggled and rubbed his hands together childishly. Assessment was restricted by his restlessness and repeated attempts to leave the room. He did not initiate speech spontaneously. In response to questions he answered monosyllabically or not at all. Responses were often idiosyncratic and irrelevant. Perseverative iteration of a single word was common. Because of the paucity of his verbal output his level of comprehension was difficult to ascertain. However, when his wife was asked whether he smoked he took a cigarette packet from his pocket and lit a

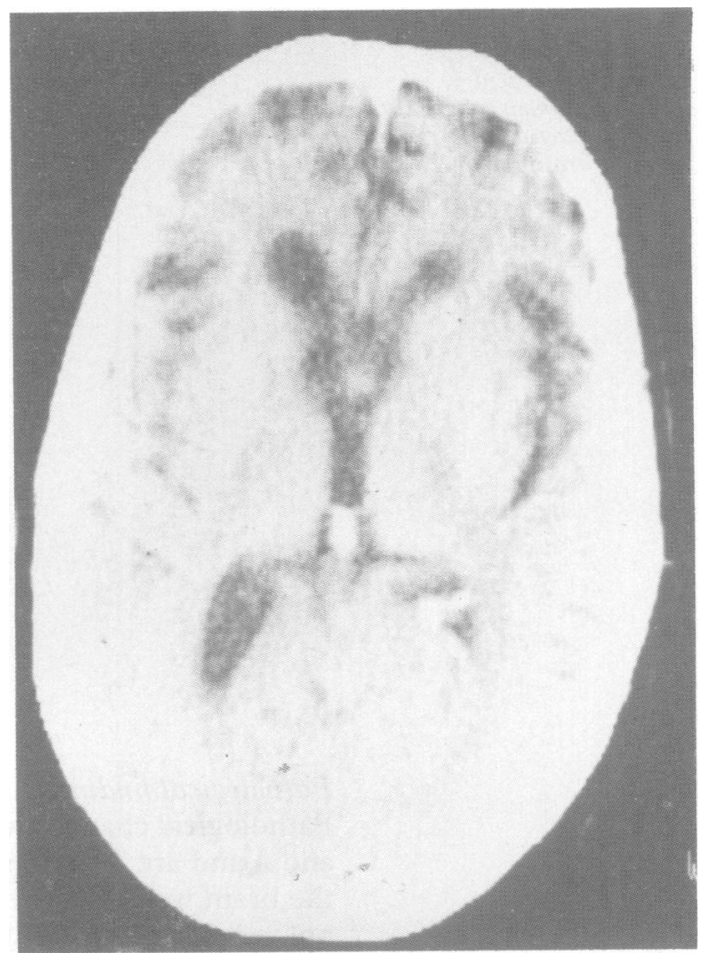

Figure 1 CT of patient 4. Atrophy is most marked in the frontal lobes.

cigarette. When she was asked whether a blood sample could be taken he removed his jacket and rolled up his sleeve. Such behaviour suggested some comprehension at least of simple nominal terms. He had a forward digit span of four digits. Occasionally he named objects to confrontation. More frequently he made verbal paraphasias, or perseverated previous responses, or else failed to respond at all. Writing was markedly perseverative. $\mathrm{He}$ failed to comply with constructional tasks.

However, features of his behaviour suggested relative preservation of spatial abilities. $\mathrm{He}$ placed his home town correctly on a map of the United Kingdom; he displayed no difficulty in locating objects in space and could negotiate his environment without becoming lost; when an article of clothing was presented to him inside out he had no difficulty rectifying this and could orient the article correctly in order to put it on. His impoverished powers of communication prohibited evaluation of his memory.

Investigations Biochemical, haematological and serological investigations were normal. Electroencephalography was normal. CT revealed cerebral atrophy, with enlargement of the ventricles and cortical sulci, the changes being most marked in the frontal lobes (fig 1). SPECT showed marked defects in tracer uptake, most prominent in the frontal lobes (fig 2). Neurophysiological investigations revealed normal motor nerve conduction and sensory action potentials. Concentric needle electromyography of the muscles of the upper and lower limbs showed multifocal fasciculations and fibrillation. Lack of cooperation prevented further evaluation but the findings were in keeping with anterior horn cell disease.

Progression $\mathrm{He}$ continued to deteriorate rapidly and died six months later, having a total duration of illness of two years. The brain was removed for examination. 
Figure 2 Single photon emission tomographic image from patient 4 Tracer uptake is markedly reduced, particularly in anterior brain regions. pyramidal cells from layers III (mainly) and V. There was also a mild fibrous astrocytosis in layers II-VI inclusive, but this was particularly heavy in the region of the U-fibres in layer VI (fig 4b), and extending into the adjacent white matter. The white matter itself showed no or slight (patient 4) demyelination with no gliosis or obvious loss of axons or of the U-fibres themselves. Similar histological changes were seen, but to a lesser extent, within the inferior gyri of the frontal cortex, the cingulate gyrus, and the anterior pole of the temporal lobe, but were absent from other cerebral cortical areas.

In the hippocampus, the subiculum and endfolium were severely gliosed, but without apparent cell loss; the Ammon's horn (CA) areas appeared normal. The basolateral nuclei of the amygdala also showed heavy gliosis without cell loss, but this was slight or absent (patient 4) in cortical nuclei and adjacent uncus. Although a slight gliosis was present within the caudate nucleus of patient 4 , the putamen, thalamus and globus pallidus were normal. The nucleus accumbens, however, was moderately gliosed in both patients. The nucleus basalis of Meynert, locus caeruleus, dorsal and median raphe appeared histologically normal in both patients. The substantia nigra showed a moderate or severe loss of nerve cells, but no Lewy bodies were present in surviving cells. Clumps of neuromelanin were prominent within the neuropil (fig 4c) and a heavy reactive fibrous astrocytosis was present (fig $4 d$ ). In the brain stem, the hypoglossus nucleus showed atrophy and loss of neurons; those of the facial and trigeminal nuclei appeared normal. The large Betz cells of the precentral gyrus were largely preserved in number though many were grossly shrunken. There was no obvious demyelination within the corticospinal tracts, in pons, medulla (pyramids) or spinal cord (lateral columns). Within the anterior horns there was gross loss of neurons at all cervical and thoracic levels, though in lumbar and sacral segments severe loss of anterior horn cells was mainly confined to medial areas (fig 4e): lateral and interomediolateral neurons appeared normal or less affected (fig 4f). In patient 4, many of the surviving anterior horn cells contained large pale inclusions within the cytoplasm (figs $4 \mathrm{e}$ and 4f). Neurons of Clarke's column appeared normal. Cerebellum and dentate nucleus appeared normal.

On silver staining, no senile plaques or neurofibrillary tangles were observed in any region of brain. Using anti (A4) amyloid staining in patient 3 alone, a single fine deposit of amyloid protein was seen only within the endfolium of the hippocampus. No tangles were demonstrated with anti-PHF staining. No Lewy, or Pick-type inclusions were observed in any cortical or subcortical neurons. An overview of the pathological change is given in table 2 .

\section{Discussion}

The four patients described exhibited a picture of profound, progressive dementia, accom- 
Figure 4 Neuropathological changes within the brain of patien 4. Layer II of the superior frontal cortex shows a pronounced spongiform change $(a)$ whereas within layers $V$ and VI there is a marked reactive fibrous atrocytosis $(b)$. Within the substantia nigra there is a severe loss of pigmented nerve cells (c) and a heavy reactive astrocytosis (d). In the spinal cord, there is atrophy and loss of medial anterior horn cells at all levels (e), whereas at lumbar levels many anterior horn cells appear preserved $(f)$. At all levels of cord, however, anterior horn cells containing large eosinophilic inclusions (arrowed) are present ( $e$, f). $a, c, e, f$

haematoxylin eosin; $b, d$ phosphotungstic acid haematoxylin. All $\times 280$.
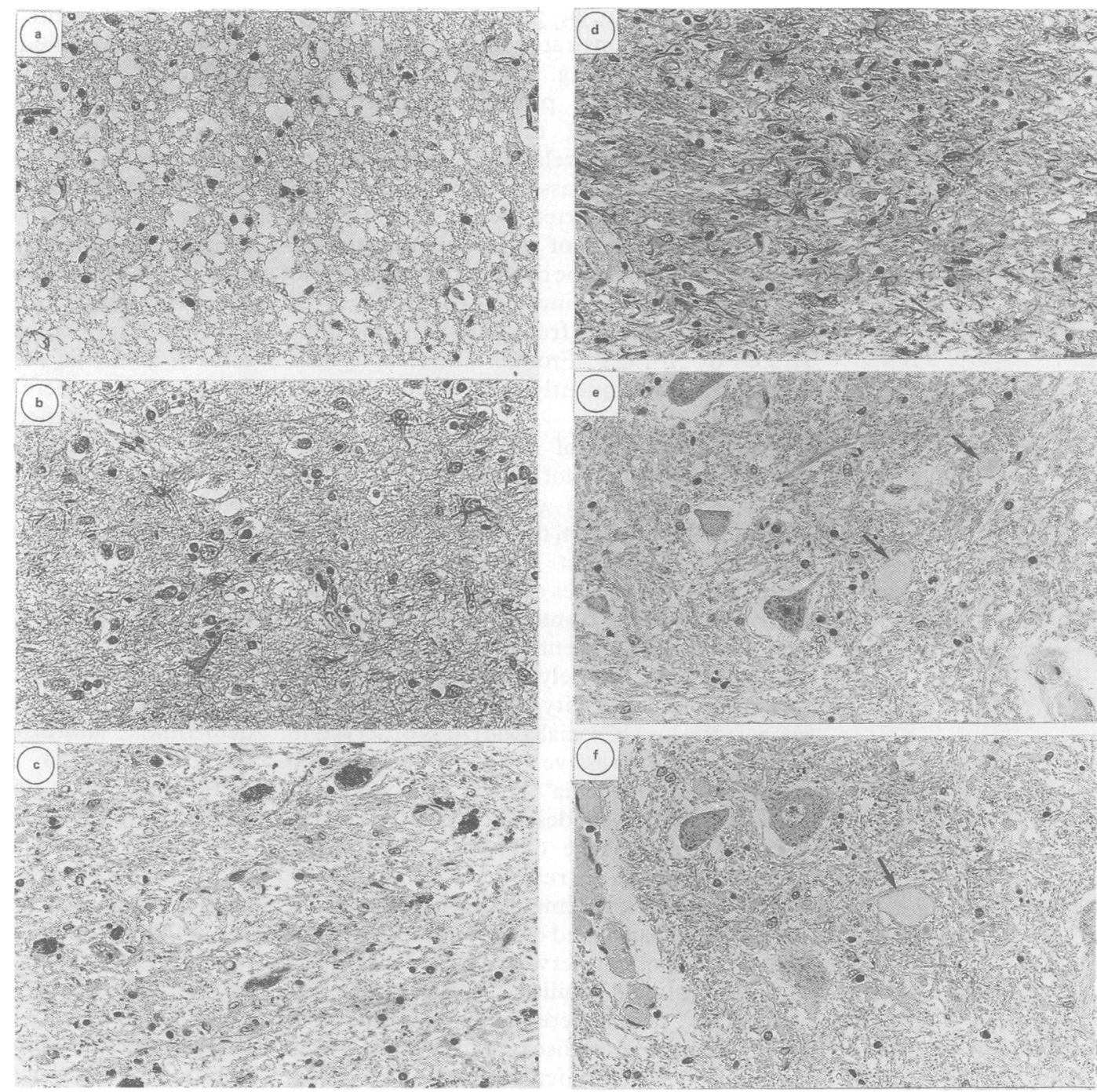

panied by the neurological findings of motor neuron disease. The mental changes were the prominent presenting feature and appeared to antedate the onset of physical signs. The pattern of dementia was similar in all four patients. Change in personality and breakdown in social conduct predominated, with disinhibition and impulsivity, apathy, unconcern and economy of mental effort being notable symptoms. Changes in eating habits,

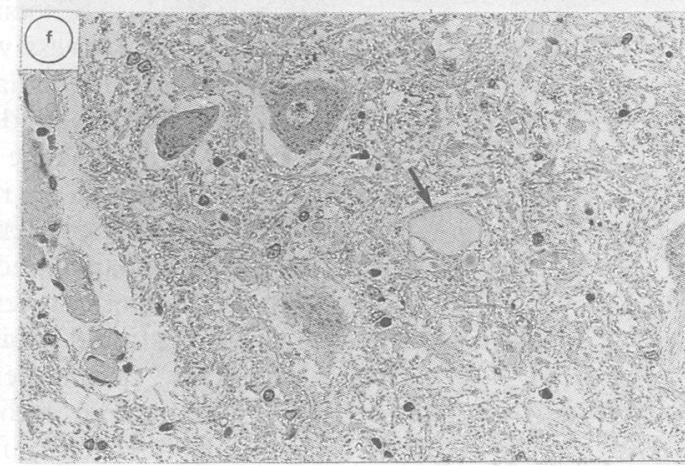

stereotyped and perseverative behaviour also occurred. Language disorder was characterised by progressive diminution in speech output, responses to questions becoming increasingly brief, stereotyped and echolalic, leading finally to mutism. Comprehension was limited by concreteness of thinking. Spatial disorder was notably absent even in advanced disease. Evaluation of memory was not feasible in patient 4 . The other patients, despite relatively

Table 2 Summary of pathological findings in patients 3 and 4

\begin{tabular}{|c|c|c|c|c|c|c|}
\hline Brain Regions & $\begin{array}{l}\text { Gross } \\
\text { tissue } \\
\text { atrophy }\end{array}$ & $\begin{array}{l}\text { Neuronal } \\
\text { atrophy }\end{array}$ & $\begin{array}{l}\text { Neuronal } \\
\text { loss }\end{array}$ & Astrocytosis & $\begin{array}{l}\text { Spongiform } \\
\text { change }\end{array}$ & Demyelination \\
\hline $\begin{array}{l}\text { Frontal cortex } \\
\quad \text { (superior, middle gyri) }\end{array}$ & ++ & + & + & ++ & ++ & $\begin{array}{l}-(3) \\
+(4)\end{array}$ \\
\hline $\begin{array}{l}\text { Frontal cortex (inferior gyri) } \\
\text { cingulate cortex } \\
\text { anterior temporal cortex }\end{array}$ & + & + & + & + & + & - \\
\hline $\begin{array}{l}\text { Posterior temporal cortex } \\
\text { parietal, occipital cortex } \\
\text { Hippocampus, amygdala }\end{array}$ & - & - & - & - & - & - \\
\hline Nucleus accumbens & - & - & - & +++ & - & - \\
\hline $\begin{array}{l}\text { Caudate, putamen } \\
\text { Globus pallidus, thalamus }\end{array}$ & - & - & - & $\stackrel{+}{\text { (caudate)(4) }}$ & - & - \\
\hline $\begin{array}{l}\text { Nucleus basalis, locus } \\
\text { caeruleus, raphe }\end{array}$ & - & - & - & 一 & - & - \\
\hline Substantia nigra & - & ++ & $\begin{array}{l}++(3) \\
+++(4)\end{array}$ & ++ & - & - \\
\hline Precentral gyrus & - & ++ & - & - & - & - \\
\hline Hypoglossus & - & ++ & $+t$ & - & - & - \\
\hline $\begin{array}{l}\text { Facial, trigeminal } \\
\text { Oculomotor }\end{array}$ & - & - & - & - & - & - \\
\hline Anterior horn (cervical) & $+(3)$ & ++ & +++ & - & - & - \\
\hline Anterior horn (lumbar) & $+(3)$ & ++ & ++ & - & - & - \\
\hline Cerebellum, dentate & - & - & - & - & - & - \\
\hline
\end{tabular}

- Absent; + Mild; ++ moderate; +++ Severe. 
poor performance on formal memory tests, were able to demonstrate some preservation of day to day memorising.

The psychological profile implicated disordered function of the anterior cerebral hemispheres, with relative preservation of function of posterior association cortices. This inference was supported by the severely impaired performance of the patients on tasks sensitive to frontal lobe dysfunction. It was also confirmed by the independent finding of reduced uptake in frontal regions demonstrated by SPECT. Frontal lobe atrophy was confirmed subsequently in two patients at necropsy.

Previous studies of dementia with motor neuron disease have not tended to focus on the pattern of dementia exhibited by affected patients. Nevertheless, the clinical descriptions available do suggest similarities with the present cases. Features of personality and conduct change are commonly described. 462324 Descriptions of patients that "wandered the streets inappropriately dressed" and had "blunting of sensibility in a ward situation"23 suggest the loss of social awareness observed in our cases. Progressive reduction in speech output $^{56}$ and echolalia ${ }^{63}$ have been noted. A further report has described altered eating habits. ${ }^{25}$ An absence of visual agnosia and apraxia has also been recorded. ${ }^{6}$

The pattern of dementia, with prominent personality change and conduct disorder in the context of well preserved spatial localisation and navigational abilities differs from the "posterior" hemisphere dementia characteristic of Alzheimer's disease, in which spatial disability is an early feature and social graces remain well-preserved until late in the disease's course. ${ }^{26} 27$ In contrast, the pattern of dementia closely resembles that of "dementia of frontallobe type", a form of cerebral degeneration distinct from Alzheimer's disease, associated with impaired frontal lobe function. ${ }^{28}$ The findings of frontal release signs on neurological examination, the normal electroencephalogram, and frontal defect on SPECT are also consistent with frontal-type dementia. The observation, reported in an independent clinical study of frontal-lobe dementia, ${ }^{29}$ of fasciculations in two of 20 patients, emphasises the clinical association between dementia of frontal lobe type and dementia with motor neuron disease.

A putative clinical distinction from frontallobe dementia is the rate of disease progression. In the four patients described a dramatic deterioration occurred over a 12 month period, the total duration of illness in patients 3 and 4 being only two years. In a review of 34 Japanese cases $^{6}$ the average duration of illness was three years. This relatively rapid course contrasts with the mean duration of eight years reported in patients with frontal lobe degeneration without motor neuron disease $\mathrm{e}^{29}$ and is more akin to the time course of classical motor neuron disease. ${ }^{1}$ It should be noted, however, that the mother of patient 2 suffered from a dementing illness of approximately 14 years duration. The pattern of her mental change strongly suggests a dementia of frontal lobe type, ${ }^{2829}$ but, unlike her son she exhibited no signs of motor neuron disease.

Pathological examination of the brain of two patients in this study revealed atrophy, most prominent in the frontal lobes, gliosis and spongiform change. Senile plaques and neurofibrillary tangles were absent, confirming the clinical impression that these patients have a disorder distinct from Alzheimer's disease. The pathological findings are strikingly similar to those described in a review of 34 Japanese cases of dementia with motor neuron disease. ${ }^{6}$ In those cases there was a mild to moderate degree of gliosis affecting particularly layer VI of the cortex, a moderate spongy state of layers I-III and a slight loss of pyramidal cells. Such changes were restricted to frontal and anterior temporal gyri. Degeneration of the substantia nigra was present in 18 patients. Pathological findings consistent with Alzheimer's disease, Pick's disease and Creutzfeldt-Jakob disease were absent.

The pathological changes in the present two cases overlap those described in frontal-lobe dementia ${ }^{3031}$ and progressive subcortical gliosis. ${ }^{32}$ Pathological reports of frontal lobe dementia ${ }^{30} 31$ have emphasised the presence of frontal atrophy, characterised by a slight spongiform change, neuronal loss and a gliosis of layers I-III. Anterior parts of temporal, cingulate and insular gyri were similarly affected, although to a lesser degree. Hippocampus and amygdala were spared. In all patients there was a mild white matter gliosis and a slight reduction in myelin. In only one case was there a slight loss of anterior horn cells but no pyramidal tract degeneration. The substantia nigra was not remarked upon.

In the report of two cases of progressive subcortical gliosis ${ }^{32}$ the frontal and anterior temporal cortex was affected by a variable cortical neuronal loss, but extensive subcortical (layer VI) and white matter gliosis with some reduction in myelin. There was some superficial cortical spongiosus. This gliosis was also present within subicular (but not CA) areas of hippocampus. The substantia nigra showed minimal neuronal loss in one case but no gliosis. Gliosis was prominent in the thalamus and inferior olives. The spinal cord was essentially normal.

Thus, the pathological changes in the frontal lobes in our two cases mirror closely those of Japanese patients with dementia and motor neuron disease; ${ }^{6}$ in addition the changes share features of frontal lobe dementia ${ }^{30}$ with layers I-III, although the deeper cortical gliosis would be more in keeping with progressive subcortical gliosis. ${ }^{32}$ However, in neither frontal lobe dementia nor progressive subcortical gliosis does nigral cell degeneration and gliosis appear prominent, nor are those latter conditions associated with significant cord alterations as in the two patients described.

Interestingly, despite the nigral changes patients did not exhibit notable extrapyramidal signs. It is possible that the rapid progression of the dementia and early death preempted the emergence of such signs. However, the severe 
gliosis seen in the nigra also occurred within frontal cortex (layer VI), nucleus accumbens, subiculum and basolateral amygdala. These changes may therefore represent degeneration within mesocortical and mesolimbic pathways, contributing to the dementia as opposed to nigro-striatal degeneration leading to extrapyramidal signs. In contrast to the severe nigral alterations the nucleus basalis, locus caeruleus and dorsal raphe were well preserved.

The nosological status of dementia with motor neuron disease is controversial. It has been thought by some authors to represent a form of Creutzfeldt-Jakob disease. ${ }^{232433}$ Other authors have suggested that the association with Creutzfeldt-Jakob disease may be inappropriate because of the absence of typical spongiform change and failure to transmit the condition to primates. $^{10}$ More recently, however, positive transmission from a single patient with "amyotrophic Creutzfeldt-Jakob disease" has been documented ${ }^{34}$ after prolonged incubation in a primate. In the four patients described in this study the normal electroencephalogram and circumscribed "frontal lobe" clinical picture contrast sharply with the strikingly abnormal electroencephalogram and widespread cognitive impairment characteristic of classical Creutzfeldt-Jakob disease. ${ }^{35}$ Moreover the spongiform change was non-specific and the striking degeneration of the substantia nigra found in this and another study ${ }^{6}$ has not been reported in transmissible subacute spongiform encephalopathy. ${ }^{10}$

Whereas some authors suggest that the condition represents a new distinct entity, ${ }^{45}$ others agree that it is a variant of motor neuron disease. ${ }^{1036}$ The pathological changes of the two patients described within the spinal cord, cranial nerve nuclei and motor cortex are consistent with motor neuron disease. However, the severity of these changes is mild and less than would be expected at necropsy. The relative mildness of the changes may reflect the short span of physical symptoms exhibited by the patients. The presence of large eosinophilic inclusions within surviving (lumbar) anterior horn cells in one case is similar to that described by others ${ }^{37}$ in motor neuron disease without dementia. Furthermore those authors described such inclusions to have anti-ubiquitin immunoreactivity. The relative brunt of disease on the anterior horn cells as opposed to the motor cortex and descending motor pathways is reflected in the Japanese studies. ${ }^{6}$

An association with motor neuron disease is supported clinically by the finding in patients with classical motor neuron disease who have no mental symptoms, of specific difficulties in carrying out cognitive tasks sensitive to frontal lobe dysfunction. ${ }^{38}$ Other authors have suggested an association with Pick's disease, ${ }^{25}{ }^{29}$ although in neither the present cases nor the large series of Japanese cases ${ }^{6}$ have the ballooned cells and inclusions pathognomonic of Pick's disease been shown. The clinical and pathological findings of the present study point to an association between dementia with motor neuron disease and dementia of frontal lobe type, ${ }^{28-31}$ suggesting the importance of genetic factors in determining the disease's expression. Dementia of frontal lobe type is known to be a strongly familial disorder, with the incidence of dementia in a first degree relative being reported as $46 \%$ and $50 \%$ in two independent series. $^{2829}$

While neurological and electrophysiological findings in patients with dementia and motor neuron disease appear similar to those of classical motor neuron disease, the pattern of dementia and nature of pathological change resemble those of dementia of frontal-lobe type. The condition may be considered to represent an interface between non-Alzheimer frontal lobe dementia and motor neuron disease. Electrophysiological studies in patients with dementia of frontal lobe type and neuropsychological evaluation of patients with motor neuron disease might elucidate subclinical or pre-symptomatic changes which would help to clarify the relationship between these conditions.

We thank Drs I Stout and G Yuill for referring patients for investigation, Dr $\mathrm{H} \mathrm{J}$ Testa for evaluation of SPECT scans, Dr W Schady and Mrs A Sheard for carrying out electrophysiological examinations and Dr $\mathrm{H}$ Reid for pathological assistance.

1 Hudson AJ. Amyotrophic lateral sclerosis and its association with dementia, parkinsonism and other neurological with dementia, parkinsonism and other

2 Hirano A, Kurland LT, Krooth RS, Lessell S. Parkinsonism-dementia complex, an endemic disease on the island of Guam. I. Clinical features. Brain 1961;84:642-61.

3 Hirano A, Malamud N, Kurland LT. Parkinsonismdementia complex, an endemic disease on the island of Guam. II. Pathological features. Brain 1961;84:662-79.

Mitsuyama Y, Takamiya S. Presenile dementia with moto neurone disease in Japan. A new entity? Arch Neurol 1979;36:592-3.

5 Mitsuyama Y. Presenile dementia with motor neurone disease in Japan: clinico-pathological review of 26 cases. J Neurol Neurosurg Psychiatry 1984;47:953-9.

6 Morita K, Kaiya H, Ikeda T, Namba M. Presenile dementia combined with amyotrophy: a review of 34 Japanese cases. Arch Gerontol Geriatr 1987;6:263-77.

7 Finlayson MH, Guberman A, Martin JB. Cerebral lesions in familial amyotrophic lateral sclerosis and dementia. Acta Neuropathol (Berl) 1973;26:237-46.

8 Pinsky L, Finlayson MH, Libman I, Scott BH. Familial amyotrophic lateral sclerosis with dementia: a second Canadian family. Clin Genet 1975;7:186-91.

9 Wikstrom J, Paetau A, Palo J, Sulkava R, Haltia M. Classic amyotrophic lateral sclerosis with dementia. Arch Neurol 1982;39:681-3.

10 Salazar AM, Masters CL, Gajdusek DC, Gibbs CJ. Syndromes of amyotrophic lateral sclerosis and dementia: relation to transmissible Creutzfeldt-Jakob disease. $A n n$ Neurol 1983;14:17-26.

11 Clark AW, White CL, Manz HJ, et al. Primary degenerative dementia without Alzheimer pathology. Can J Neurol Sci 1986;13:462-70.

12 De Renzi E, Faglioni P. Normative data and screening power of a shortened version of the token test. Cortex 1978;14:41-9.

13 Kaplan E, Goodglass H, Weintraub S. The Boston Naming est. Philadelphia: Lea and Febiger 1983

14 Money J, Alexander D, Walker HT. Manual for a standardised road-map of direction sense. Baltimore: John Hopkins University Press 1965.

15 Warrington Recognition Memory Test. Windsor: NFERNelson Publishing Co, 1984.

16 Wechsler D. The Measurement of Adult Intelligence. Baltimore: Williams and Wilkins, 1944.

17 Nel̄son $\bar{H}$, O'Connell A. Dementia: the estimation of 
premorbid intelligence levels using the new adult reading test. Cortex $1978 ; 14: 234-44$

18 Nelson HE. A modified card sorting test sensitive to frontal lobe defects. Cortex 1976;12:313-24.

19 De Renzi E, Faglioni P, Savoiardo M, Vignolo LA. The influence of aphasia and of the hemisphere side of the cerebral lesion on abstract thinking. Cortex 1966;2: $399-420$.

20 Becker JT, Butters N, Rivoira P, Miliotis P. Asking the right questions: problem solving in male alcoholics and male alcoholics with Korsakoff's syndrome. Alcoholism; Clinical and Experimental Research 1986;10:641-6.

21 Jones-Gotman M, Milner B. Design fluency: the invention of nonsense drawings after focal cortical lesions. Neuroof nonsense drawings after

22 Shallice T, Evans ME. The involvement of the frontal lobes in cognitive estimation. Cortex 1978;14:294-303.

23 Sherratt RM. Motor neuron disease and dementia: probably Creutzfeldt-Jakob disease. Proc $R$ Soc Med 1974;67. $1063-4$.

24 Allen IV, Dermott E, Connolly JH, Hurwitz LJ. A study of a patient with the amyotrophic form of Creutzfeldt-Jakob disease. Brain 1971;94:715-24.

25 Dickson DW, Horoupian DS, Thal LJ, Davies P, Walkley S, Terry RD. Kluver-Bucy syndrome and amyotrophic lateral sclerosis: a case report with biochemistry, morphometrics and golgi study. Neurology 1986;36: morphome

26 Cummings JL, Benson DF. Dementia: a Clinical Approach Boston: Butterworths 1983:35-57.

27 Neary D, Snowden JS, Bowen DM, et al. Neuropsychological syndromes in presenile dementia due to cerebral atrophy. J Neurol Neurosurg Psychiatry 1986; 49:163-74

28 Neary D, Snowden JS, Northen B, Goulding P. Dementia of frontal-lobe type. J Neurol Neurosurg Psychiatry 1988;51:353-61.

29 Gustafson L. Frontal lobe degeneration of non-Alzheimer ype. II. Clinical picture and differential diagnosis. Arch Gerontol Geriatr 1987;6:209-23.

30 Brun A. Frontal lobe degeneration of non-Alzheimer type. I. Neuropathology. Arch Gerontol Geriatr 1987;6:193-208.

31 Englund E, Brun A. Frontal lobe degeneration of nonAlzheimer type. IV White

32 Verity MA, Wechsler AF. Progressive subcortical gliosis of Neumann: a clinicopathologic study of two cases with review. Arch Gerontol Geriatr 1987;6:245-61.

33 Van Rossum A. Spastic pseudosclerosis (Creutzfeldt-Jakob disease). In: Vinken PJ, Bruyn GW eds. Handbook of disease). In: Vinken PJ, Bruyn GW eds. Handbook of Ylinical Neurology. Diseases of the Basal

34 Connolly JH, Allen IV, Dermott E. Transmissible agent in the amyotrophic form of Creutzfeldt-Jakob disease. J Neurol Neurosurg Psychiatry 1988;51:1459-60.

35 Matthews WB. Creutzfeldt-Jakob disease. In: Frederiks JAM, ed. Handbook of Clinical Neurology: Neurobehavioural Disorders Amsterdam: Elsevier Science Publishers 1985;46:289-99.

36 Horoupian DS, Thal L, Katzman R, et al. Dementia and motor neuron disease: morphometic, biochemical and golgi studies. Ann Neurol 1984;16:305-13.

37 Leigh PN, Anderton BH, Dodson A, Gallo J-M, Swash M, Power DM. Ubiquitin deposits in anterior horn cells in Power DM. Ubiquitin deposits in anterior horn cells

38 David AS, Gillham RA. Neuropsychological study of motor neurone disease. Psychosomatics 1986;27:441-5.

39 Brion S, Psimaras A, Chevalier JF, Plas J, Masse G, Jatteau O. L'association maladie de Pick et sclerose laterale amyotrophique. Encephale 1980;6:259-86. 